\title{
Research on the Platform Business Model of Cultural Industries in the Era of "Internet+"
}

\author{
Baifu Chen', Hui Yang², Xiaofan Xiao² \\ ${ }^{1}$ School of Economics and Management, Dongguan University of Technology, Dongguan, China \\ ${ }^{2}$ School of History and Culture, Hunan Normal University, Changsha, China \\ Email: chenbeifu88@126.com
}

How to cite this paper: Chen, B.F., Yang, H. and Xiao, X.F. (2018) Research on the Platform Business Model of Cultural Industries in the Era of "Internet+". Open Journal of Social Sciences, 6, 289-300. https://doi.org/10.4236/jss.2018.63021

Received: January 1, 2018

Accepted: April 6, 2018

Published: April 9, 2018

\begin{abstract}
In recent years, the emergence of new technologies, such as "internetwork", "the Internet of things", "cloud computing", has overthrown the business model of traditional cultural industries. It promotes the utilization of Internet connectivity and open logic, and contributes to implementing the strategy of platform business model of cultural industries. Under the background of the "Internet+", this paper analyzes the process of value creation of platform business model of cultural industries from four aspects, including value proposition, value creation, value delivery as well as value realization. Michael Porter's Five Forces Model is applied to explore the innovation motivation of the platform business model of culture industries.
\end{abstract}

\section{Keywords}

"Internet+", Platform Cultural Industry, Business Model of Cultural Industries

\section{Introduction}

Up to now, Internet technology has been widely used in various industries and has become an indispensable technical support and service platform for enterprises. In November 2012, Yi Guan, the chairman and CEO of Analysis International, first proposed the concept of "Internet+", and then Internet thinking soon became a popular buzzword in 2014. At the third meeting of the 12th National People's Congress, Li Keqiang, the Premier of the State Council, advanced the "Internet+" action plan, and the "Internet+" has been formally written into the Report on the Work of the Government. After the emergence of the Internet technology, the human beings stepped into a new period. It has changed the external environment, and promoted fundamental changes of enterprise organiza- 
tion structure, business model as well as management mode. Peter Drucker, known as "the father of modern management", once said that the competition between businesses today is not competition between the products, but between the business models. Michael porter, a professor of competitive strategy at Harvard Business School, says that there is no business that can't make money, but a model that doesn't make money. Therefore, Business model is crucial for industrial development and enterprise competition. For example, in March 2015, The state council promulgated some opinions on deepening the systems and mechanisms to speed up the implementation of innovation-driven development strategy, which explicitly put forward to advance the overall innovation of science and technology, management, brand, organization, and business model.

As an emerging industry, the development of cultural industry is still in its infancy. What's more, the emergence of new technologies, such as the Internet, the Internet of things, cloud computing and so on, has overthrown the business model of traditional cultural industry and has induced the cultural content production, culture dissemination channels, and cultural consumption changing dramatically. In addition, the Internet, across time and space, has broken the geographical limits and accelerated the integration development of different industries. It also does favor to integrate the different formats of cultural industries and to drive the reform of internal management of cultural industries. Lawrence Lessig considered that: "the combination of digital technology and Internet can produce a very active and more competitive market culture construction development; the market can absorb more creators, who show a variety of creativity." [1]. Therefore, under the background of "Internet+", if platform cultural enterprises would like to maintain sustainable business competitiveness and profitability in the complex market environment, it is inevitable and exigent to research on the business model.

\section{Literature Review}

In fact, the whole cultural industry of China is in a dilemma, and the theoretical research has lagged far behind the practice development. In recent years, the study of cultural industry business model has gradually increased in the academic circles, and the objects of the research also expand-from basic theory such as the concept and elements to innovation dynamical mechanism, the types of business model and innovation path selection. In addition, with the emergence of new technologies, the changing of time and the support of various theories, the cultural industry business model is in line with the age and then the study which under the background of the Internet mushrooms. From the perspective of environmental change of the mobile Internet business model, Xiao Zhenbo (2015), comparing with the traditional business model, explored the advantages of multiple and changing consumer behavior, and put forward the basic principle and path selection of cultural industry business model innovation under the background of mobile Internet [2]. Wang Hong and Sun Min (2015) 
argued that in the era of mobile Internet, the business model of cultural industry, in summary, was mainly composed of seven elements, including the target customer, distribution channel, value proposition, creative ability, resource allocation, capital operation and value communication. Moreover, the innovation path of cultural industry business model is discussed from four key factors as following: target customer, value proposition, value communication and distribution channel [3]. Huang Jinzong and Chen Shaofeng (2016) discussed the new characteristics of the Internet business model and summarized the new form of the business model of Internet cultural industry by thinking about the Internet culture industry [4]. Therefore, from the research trend of the cultural industry business model, the cultural industry business model is constantly expanding along with the progress of the society, which is the research scope. However, through reviewing the related literature of cultural industry business model, it is easy to find that the depth and breadth of the research on the business model of cultural industry is not enough, just focusing on the introduction of flatness and the three-dimensional research rarely. Cultural industry is an interdiscipline, and the researchers, due to their own research on different fields, proposes different opinions about cultural industry business model, such as definition, constituent elements and so on. In a result, it's difficult to form a unified research framework, and it's not conducive to the integrity research of the cultural industry business model.

In addition, the research on the innovation path is mainly based on the value creation and elements, which is lack of dynamics and systematicness. Moreover, the introduction of "Internet+" action plan in 2015 promoted the development of internet cultural enterprises and many internet cultural companies appeared in China. However, the research on the business model of cultural industry on the "Internet+" background is relatively weak, so the relevant academic research often lags behind practice. In general, the research on the business model of cultural industry under the "Internet+" background is not mature, and it is necessary to enhance the depth and breadth of the research.

\section{The Logic of Value Creation}

The business model of cultural industry is based on the comprehensive consideration of the internal and external environment of the cultural enterprises. In order to meet the customer value as the center and to correctly handle the competition and cooperation between stakeholders, it is important to realize the transfer and obtain of economic and cultural value through a series of process. The business model of cultural industry mainly includes ten elements as following: value proposition, key business, core resources, important cooperation, cost structure, channel access, customer relationship, customer segmentation, source of income and system guarantee. Under the background of "Internet +", different models formed as free model under the customer's drainage, the long tail model under the services superposition, cultural authorization and Internet cul- 
ture finance model supported by the elements, and electrical business models and culture sharing models under value realization. Business model is the logic of profit and the earning of profit is the whole process of value creation. Thus, the value creation logic of cultural industry business model includes four processes, such as value orientation, value creation, value delivery and value acquisition.

In this paper, the analysis of value creation logic of the cultural industry business model, is mainly through the combination of the process of business model value creation with the elements of cultural industry business model in order to form a cultural industry system of value creation. Each link of value creation corresponds to the corresponding elements of the business model in the whole value creation logic analysis framework. Cultural industry, as a spiritual industry or creative industry, emphasizes the creative and spiritual attributes of cultural content. The value orientation of cultural industry, is mainly based on the internal and external environmental factors to determine the value proposition of cultural enterprises, subdividing customer at the same time, and according to the customer's consumption needs and preferences to help cultural enterprises to determine what kind of products for our customers as shown in Figure 1. Moreover, the raise of cultural industry value proposition needs to combine the internal resources of enterprises to create value. The key resources, important cooperation and core resources in the value creation of cultural industry, are all in this link. After value creation, the process of value delivery must be carried out in order to enter value capture. Value delivery is a two-way transmission between cultural enterprises and customers. Meanwhile cultural enterprises pass the value proposition successfully to customers through channels. Similarly,

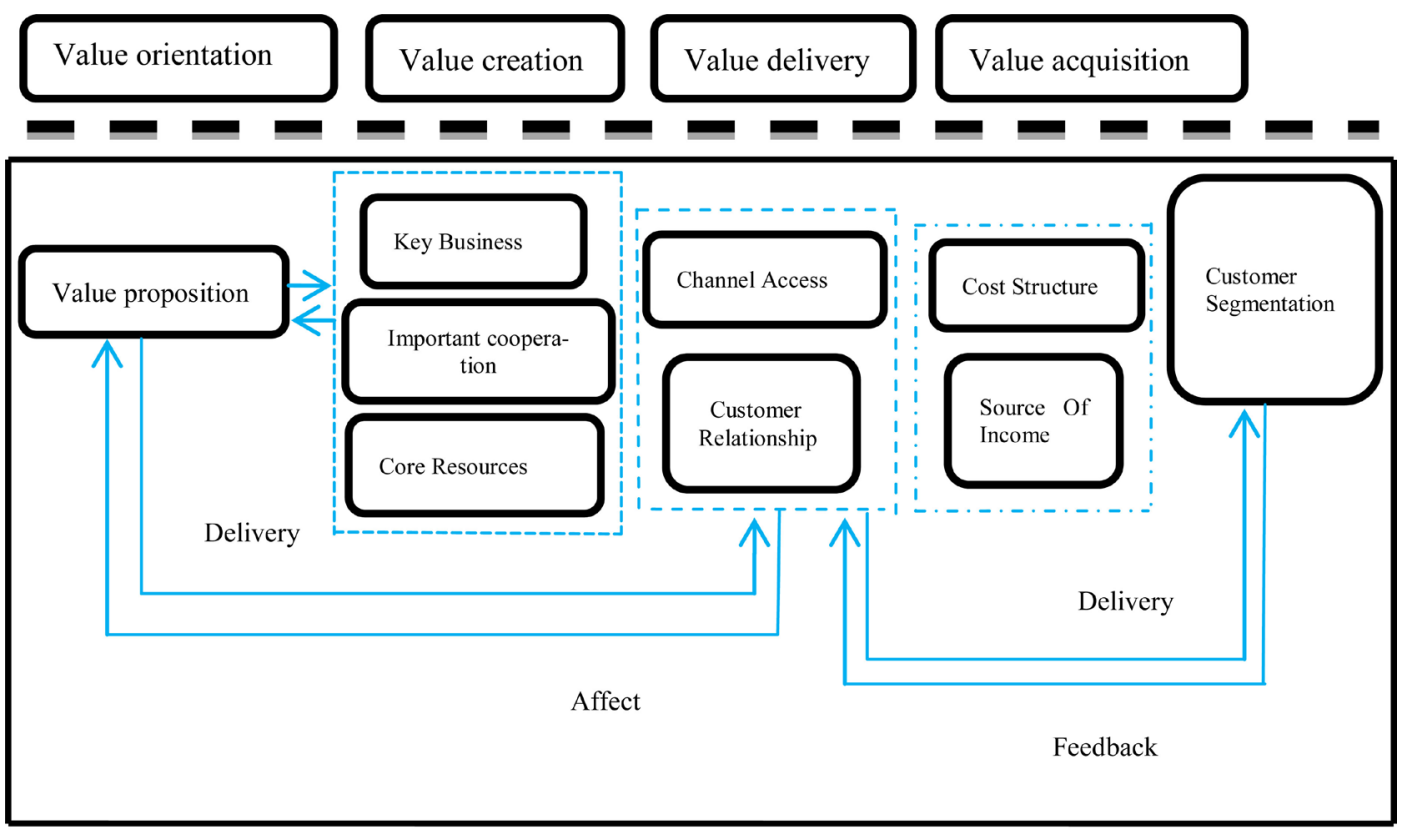

System guarantee

Figure 1. Value creation logic of cultural industry business model. 
according to relevant data, such as customer's preferences to build customer relationship database, cultural enterprises apply the big data analysis for the data of customers, so as to make targeted production customers' favorite cultural products. Value acquisition is the ultimate goal of the cultural industry business model. Cultural enterprises obtain corresponding profits by providing cultural products or services, in order to maintain the survival of cultural enterprises and to expand the scale of cultural enterprises. The production and operation process of cultural enterprises can generate a large amount of expenses and form a certain cost structure. While the sales of cultural products and services will inevitably receive corresponding income. At the value acquisition stage, cultural enterprises are the capital surplus after balancing their own cost structure and income source, which can provide financial support for the related activities of cultural enterprises. Meanwhile, the system guarantees run through the whole process of the value creation of cultural industry's business model to coordinate the development of cultural industry.

The building of value creation system of cultural industry, which is based on value creation process and the business model elements, can make the cultural enterprises correctly, grasp its own business model and has a very clear understanding for each link of business model. In addition, it is of great significance for the healthy and rapid development of cultural industry.

\section{Innovative Dynamic Analysis of Cultural Industry Business Model}

At present, China's cultural industry is developing rapidly, for example in 2010, the added value of cultural industry was 1105.2 billion RMB, accounting for 2.75 percent of GDP. And then in 2015 the added value of the cultural industry was 273.5 billion RMB accounting for 3.97 percent of GDP. And the added value of China's cultural industry reached 3025.4 billion RMB in 2016, which accounted for 4.07 percent of GDP in 2016. It can be found that the development of cultural industry in China is relatively fast. However, in the process of China's cultural industry development, there are certain problems, such as the lack of innovation ability of cultural industries and the homogeneity of cultural products. In order to promote the healthy development of cultural industry and to obtain the enterprise competitive advantage, we should take effective cultural industry business model innovation and make analysis of the innovation dynamic mechanism of cultural industry business model.

\subsection{Basic Explanation of the Innovation Dynamic Mechanism of Cultural Industry Business Model}

In the information age, macro and micro environment is changing rapidly, the business model of cultural enterprises is facing creative destruction after a relatively stable stage. As a new form of innovation, the formation of new business model must be driven by certain motive forces. At the same time, the business 
model as a model of value creation determines how business activities bring profit to the enterprise. The strategy of the enterprise reflects a series of business management including the daily business decision of the enterprise and the long-term plan decision [5]. The business model and strategy are all represent that the enterprise would take what kind of action and the formulation of the rules to create value for the enterprise growth. So there is a certain relationship between business model and strategy, which means a process of mutual promotion. Namely, successful business model must be based on the successful enterprise strategy and successful corporate strategy inevitably needs the support of mature business model. Seddon and other scholars pointed out that business model was a microcosm of corporate competitive strategy [6]. It is the basic detail of an enterprise's activity system that aims at the value proposition of its various stakeholders while creating and providing value for customers [7]. In addition, A Chinese scholar, Luo Min (2009) considered that the business model was a strategic intention and an achievable structure system [8]. In other words, it was a collection of institutional arrangements for an organization to obtain excess profits through integrating the organization itself, customer, supply chain partner, employee and stakeholders under the premise of explicit external assumptions, internal resources and capabilities. That is to say, this business model can be integrated with the enterprise strategy as a analytical framework to promote for the development of enterprises, and strategic changes under the change of enterprise environment can bring qualitative change to enterprise business model development and can promote the innovation of business model through enterprise strategy change from different aspects, so as to obtain maximize value. Porter's Five-force Analysis model is mainly to analyze the basic competitive situation of enterprises, which is an effective enterprise strategy and can effectively analyze the competitive environment of customers. Therefore, the following is mainly based on the porter's five force analysis model to explain the dynamic mechanism of the innovation of cultural industry business model.

\subsection{Innovative Dynamic Analysis of the Cultural Industry Business Model Based on Michael Porter's Five Forces Model}

In the 1980s, Michael Porter proposed the Five-force analysis model that there are five forces in the industry determining the scale and degree of competition, including Bargaining Power of Suppliers, Bargaining Power of Customers, Threat of New Entrants, Threat of Substitution and Intensity of Rivalry. As a competitive strategy model, Porter's Five-force model can effectively analyze the competitive environment of enterprises. Meanwhile it is also the classic tool of industrial structure analysis. In addition, Porter's Five-force analysis can also perform static scanning of the industry's profitability and attractiveness. In a word, Porter's five-force model is an effective method of strategic level that can provide guidance for the value creation and development of enterprises. The rapid development of enterprises can not be separated from the external envi- 
ronment. Instead, only a comprehensive grasp of the external environment of the enterprise can enterprise take targeted measures to promote the innovation of the internal business model, then adapt to external changes and create value for enterprises.

Nowadays, cultural enterprises in our country are not mature and there are still few cultural enterprises with good business model and growth. Most cultural enterprises have problems such as weak market awareness, low efficiency of cultural resources utilization and insufficient innovation in business model. In order to promote the innovation of cultural industry business model and to enhance the overall strength of cultural enterprises, dynamic analysis of business model innovation shows particularly important. The following will analyze the development dynamics of the cultural industry business model from the five main parts of porter's Five-force model as shown in Figure 2.

\section{1) Threat of Substitution}

Cultural industry is an activity that provides cultural entertainment and other spiritual products or services to the public. Due to its own creative and peculiarity, the alternative threat of external industry is small and the main alternative threat is in the cultural industry, so it has certain irreplaceability. There is a threat of substitution when a product or service in a cultural enterprise squeezes out another cultural product or service and it can effectively meet consumers' needs. The substitution of cultural products sets the cut on the company's pricing of profits for the product. The attraction of cultural substitutes makes the profit space of existing cultural products narrow and is threatened by strong competition. Facing the fierce threat of substitutes, cultural enterprises, in order to be able to get the user's favor, need cultural products as much as possible to reduce the production cost, improve the value of the product content and increase the added value of cultural products, so as to meet the spiritual needs of consumers. The acquisition of good competitive advantage requires the innovation

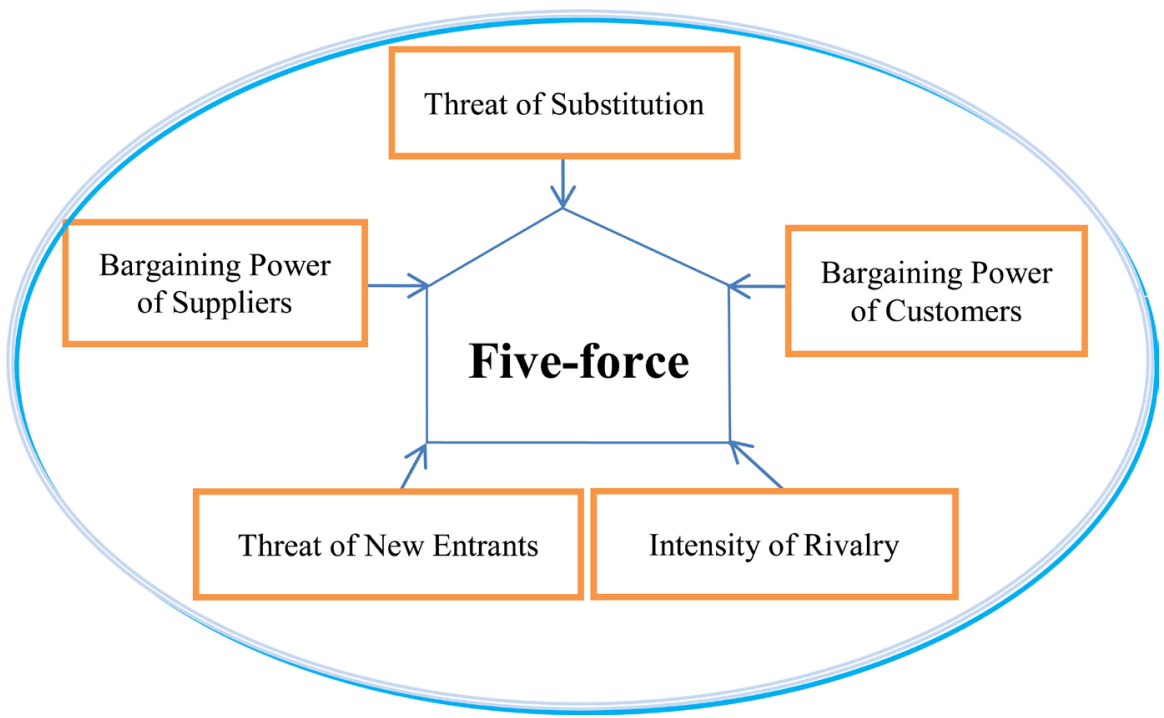

Figure 2. Porter's Five-force analysis model. 
of cultural enterprise business model to adapt to the changing times. This pattern of cultural products also adapts to the substitution of cultural industries, such as the initial independent development of the cultural leisure, and entertainment industry improves the substitution ability of products in different subdivisions. In order to achieve the transformation and upgrading of the industry, the cultural industry has developed a new type of entertainment industry and has created a cultural industry business model of the whole industry chain. The form of multi-cultural entertainment is mainly due to the similar audiences in literature, animation, film and television, music and other industries, which can promote the combination of industries to obtain the economic benefit of the whole industry, and realize the long tail value of cultural products. It also shows that the threat of cultural substitutes can promote the innovation of cultural enterprises in business model.

\section{2) Bargaining Power of Customers}

The ultimate flow of cultural products or services is to enter the market and reach consumers. Bargaining Power of Customers is mainly based on consumer behavior to influence the profitability of cultural enterprises including consumer demand for cultural product quality factors and consumer demand and so on. Meanwhile the change of consumer demand also affects the production of cultural enterprises and the innovation of business model. For example Deloitte consulting company (2002) found that in order to meet the changing consumer behavior, the enterprise must adjust the business model accordingly rather than the changes in the technical regulations and policies proposed by many scholars when studying the business model innovation process of 15 enterprises [9]. Today's market is a customer-oriented buyer's market, the acquisition of customer flow is the basis of the development of cultural enterprises, and the clear consumer demand is the driving force of cultural enterprises to conduct business model innovation behavior. This also suggests that the emergence of new consumer demand will inevitably lead to the emergence of new products. These new products tend to be more creative and to satisfy consumers' personalized needs than traditional cultural products. In order to attract consumers' attention, traditional culture enterprises will innovate in business model and change the original value creation structure to enhance the competitive advantage of enterprises. For example, the WO Music of China Unicom adjusts its development strategy and innovates the business model to the change of consumer demand, using the advantages of their own operators to establish strategic partnership with the well-known Internet music to launch WO+ music APP directional flow products. In this way, China Unicom started a new Internet music charting model and won the top brand impact award of 2016 China mobile Internet "gold fingertip".

\section{3) Intensity of Rivalry}

There are competing phenomena among enterprises in the culture industry that the main performance is in the product price, the product's originality and 
experiential and so on. If other cultural enterprises have strong competitiveness, they will inevitably have an important influence on the development of another cultural enterprise. Some enterprises have adopted some ways to increase the competition among existing enterprises such as price competition, product innovation and product differentiation. Therefore, in order to gain comparative advantage in the fierce competition in the industry market, cultural enterprises will improve their competitive ability and innovate business models through innovative ways. It indicates that Intensity of Rivalry influences the speed and quality of the innovation of business model of cultural enterprises. In addition, Venkatraman and Henderson (2008) studied the pressure promotes innovation of business models based on competition. They pointed out the competitive factors of the innovation of business model and thought that the enterprise would generate the demand for the innovation of business model in the pressure of technological reform and the change of the way of operation accumulating to the critical point [10]. Under the competition environment of enterprises, cultural enterprises can reduce the cost of cultural products and enhance their innovation by reselecting the combination of resources and remaking production to realize its own value proposition. In essence, Intensity of Rivalry is an important force to promote the innovation of the cultural industry business model.

\section{4) Threat of New Entrants}

The development and expansion of cultural enterprises are bound to be threatened by the forces of all parties, including policy support, the emergence of new technologies and other factors as shown in Figure 3. The entry of new entrants of cultural products is partly driven by government policies and technological innovation. In order to encourage the development of cultural enterprises, the government will give cultural enterprises much policy support and the enterprise's entry can make a great profit due to the great development space of cultural market. At present, many enterprises have entered the cultural industry, among which the most famous ones belong to the comprehensive transformation of Wanda Corporation. After investing in the cultural industry in 2005,

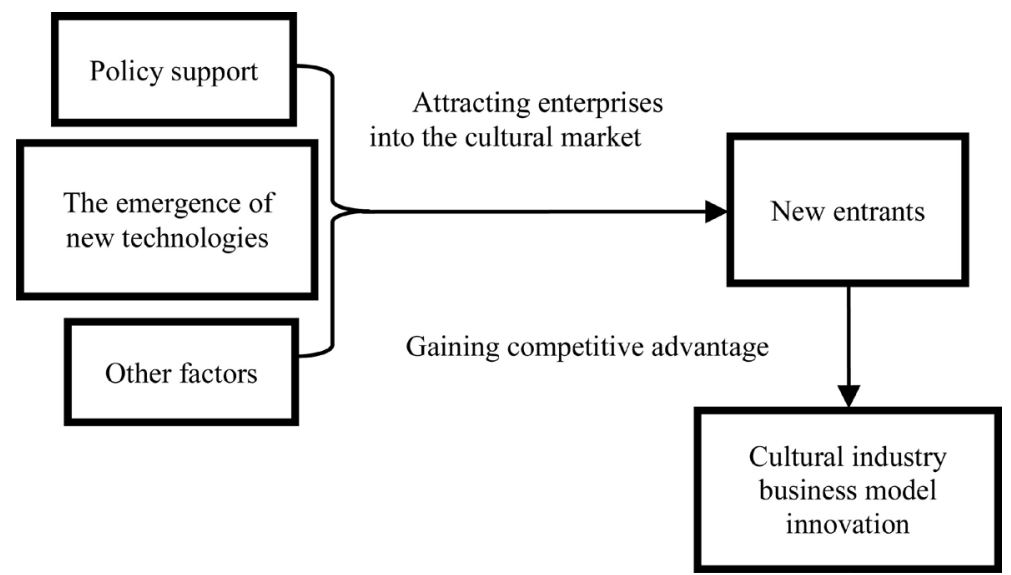

Figure 3. Relationship between potential competitors and cultural industries' business model innovation. 
Wanda group has totally invested in the cultural industry and has achieved great success. Wanda group's operating income in 2016 totaled 254.98 billion RMB, of which business reached 143.02 billion accounting for about $56 \%$ of the total and cultural group reached 64,110 million RMB accounting for about $25 \%$ of the total [11]. With the rapid development of information technology, any enterprise and individual can use the Internet to access information and play a role in the development of cultural industry. These favorable conditions have pushed the relevant enterprises into the cultural market and have more new entrants. Cultural enterprises can innovate their business models for the sake of competitive advantage. Fundamentally, the new entrants are largely dependent on technical innovation and policy support and so on in the fierce competitiveness to gain the competitive advantage in the business model innovation.

\section{5) Bargaining Power of Suppliers}

Bargaining Power of Suppliers mainly refers to the ability of the supplier to influence the profitability and product competitiveness of existing enterprises in the industry by increasing the input factor and reducing the quality of the unit's value (Figure 4). The raw materials of cultural products generally require the supply of upstream enterprises. For cultural derivatives, the upstream enterprises still need to provide ideas. As cultural products supplier adopts advanced technology and strengthen the inputs to the creative elements, cultural enterprises will raise prices to obtain the value of itself. At this time the supplier has the initiative of the buyer and the seller. Ultimately the increase in the cost of producing the raw materials for cultural products forces the increase in prices of cultural products that cannot keep up with costs and lose profits. For the vantage,

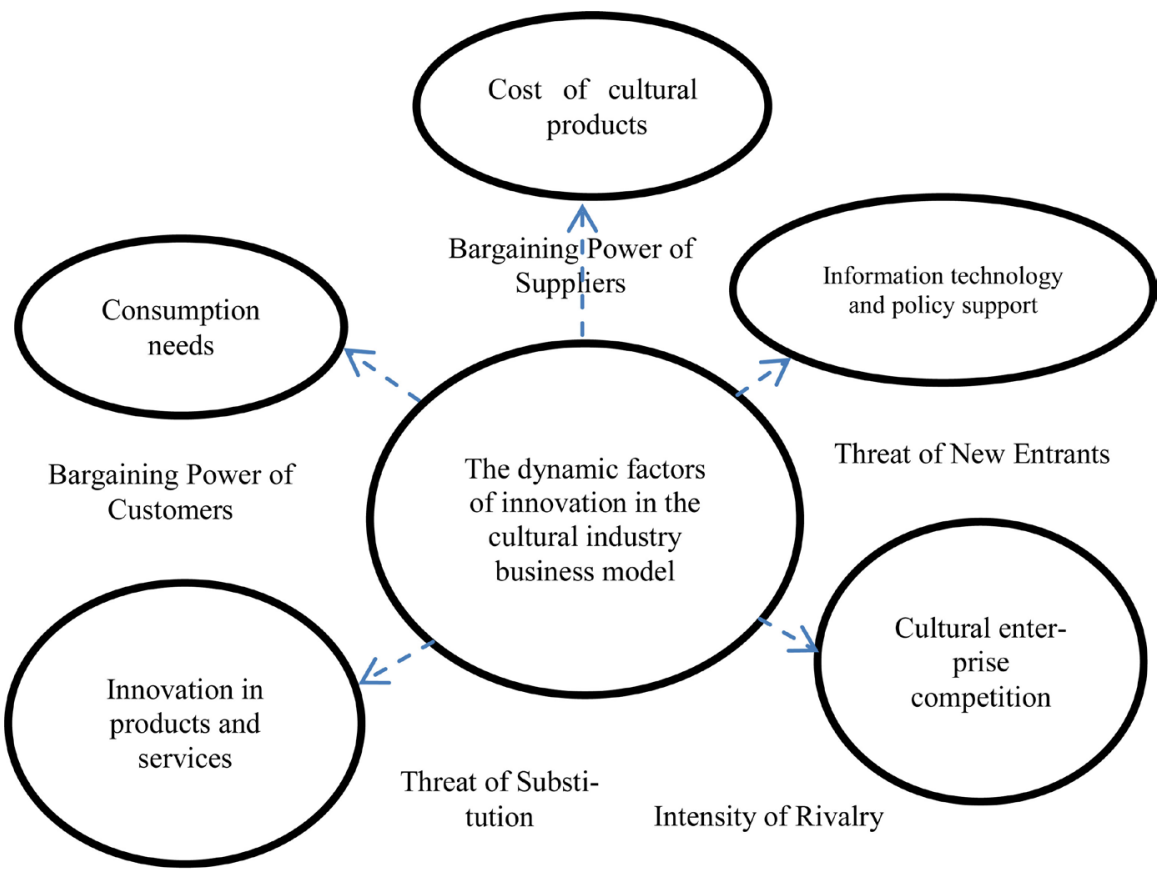

Figure 4. Relationship between porter's five forces model and cultural industries' business model innovation. 
if the number of raw material suppliers of cultural products is less than the number of enterprises purchased, the concentration of cultural products suppliers will be higher than the concentration of purchasing enterprises. At this moment, cultural products suppliers have strong bargaining power to form a monopoly on the raw materials of a certain cultural products, which has a huge impact on the profitability of cultural enterprises. So cultural enterprises in order to change the monopoly suppliers will take measures to reduce the production cost or make business model innovation as soon as possible and use the model of the whole industry chain of cultural products to reduce dependence on suppliers of raw materials.

\section{Conclusions and Prospects}

The cultural industry business model is a series of activities that cultural enterprises can create value in the competitive market environment, which is the result of the value network and resource integration of cultural enterprises. Value create logical analysis of platform cultural industry business model is more conducive to the business logic and the internal mechanism of cultural enterprises to understand the value creation of the business model, and play integration and systematic operation of cultural enterprises, at the same time, effectively dealing with the threats posed by complex and changeable environments. Moreover, the "Internet+" has provided great development opportunities for the development of the cultural industry that the emergence of the platform cultural industry business model is the result of the cultural industry adapting to the Internet environment. As a creative economy with creativity as the core factor, cultural industry will face more and more potential competitors under the active promotion of national policies. Therefore, cultural enterprises should seize opportunities, face challenges and actively respond to challenges and opportunities brought by new technologies. What's more, from the development point of view, cultural enterprises should attempt to cope with the changing of the development of the market and integrate into the new cultural industry, so as to find innovative conditions and create new business models from the dynamic mechanism of business model. Firstly, business model innovation is based on the market, consumer demand change, core resources and key ability to seize the opportunity to realize the enterprise value proposition in the gap of market. Secondly, cultural enterprises can enhance enterprise competitive advantage by conducting external cooperation and sharing and building an enterprise relationship network of win-win cooperation and value sharing. When the "Internet+" and the "platform economy" expand the enterprise boundary. In general, with the further development of mobile Internet, the business model of cultural industry will present new features, new types, new changes and new trends.

\section{References}

[1] Lessig, L. (2009) Free Culture: The Future of the Creative Industry. Central Pub- 
lishing House, Beijing.

[2] Xiao, Z.B. (2015) Innovation of Cultural Industry Business Model in the Context of Mobile Interconnection. Modern Communication, No. 6, 167-168.

[3] Wang, H. and Sun, M. (2015) Business Model and Innovation Path of Cultural Industry in Mobile Internet Era. Study and Practice, No. 10, 121-126.

[4] Huang, J.Z. and Chen, S.F. (2016) Innovation of Business Model of Internet Cultural Industry. Fujian BBS Humanities and Social Sciences Edition, No. 2, 63-68.

[5] Lu, H.J. and Liu, H. (2011) Analysis of Business Model and Strategic Relationship Based on Matching Perspective. Journal of Southeast University (Philosophical Social Science Edition), No. 2, 46-52.

[6] Seddon, P.B., Lewis, G.P., Freeman, P., et al. (2004) The Case for Viewing Business Models as Abstractions of Strategy. Communications of the Association for Information Systems, 13, 427-442.

[7] Porter, M.E. (1996) What Is Strategy? Harvard Business Review, 86, 926-929.

[8] Luo, M. (2009) Theoretical Framework of Business Model. Contemporary Economic Management, No. 11, 1-8.

[9] Deloitte Research (2002) Deconstructing the Formula for Business Model Innovation. http://www.doc88.com/p-1826024507633.html

[10] Xu, P. (2013) Research on the Influencing Factors of Business Model Innovation Based on Online Consumption. Xi'an University of Electronic Science and Technology, Xi'an.

[11] Wanda Corporation's 2016 Work Report-Wanda's Official Website. http://www.wanda.cn/2017/2017_0115/34435.html 